\title{
Avaliação e suas Dimensões no Processo de Ensino Aprendizagem: Uma Dinâmica Pedagógica na Visão de Hoffmann, Libâneo, Luckesi, Mello e Souza e, Sousa
}

\author{
Flávia Maria da Silva ${ }^{1}$ Cícera Alves Nunes ${ }^{2}$
}

\begin{abstract}
Resumo: O presente artigo fez uma análise sobre os conhecimentos e teorias relacionados à avaliação e suas dimensões no processo de ensino aprendizagem, tendo como objetivo compreender essas dimensões. Sintetizando sobre as mesmas na práxis pedagógica diária, a avaliação no processo de ensino aprendizagem, bem como a avaliação numa visão mediadora da aprendizagem com base em obras de Hoffmann (2017, 2019), Luckesi (1999, 2011), Libâneo (2006), Mello e Souza (2005) e Sousa (2000). A partir das análises teóricas e da pesquisa de campo entendemos que a avaliação é um aspecto próprio e inseparável da educação, através da avaliação é possível verificar se o ensino foi eficaz para que alcançasse a aprendizagem dos alunos, deve também ser considerada como algo que contribui para o desenvolvimento intelectual, social e moral dos alunos. Notamos que atualmente a avaliação ainda é praticada com a finalidade de aprovar ou reprovar, como fim classificatório, porém felizmente vem ganhando uma nova roupagem, sendo entendida de uma forma mais abrangente, uma vez que é um dos componentes mais significativos do processo de ensino aprendizagem. Então, mesmo sabendo que o processo de avaliar é complexo o professor deve ser reflexivo, um polivalente na sua atuação, deve se autoavaliar continuamente, pois como mediador do processo de ensino aprendizagem é necessário que se tenha uma formação e ação voltadas para o bem estar e desenvolvimento do aluno, ou seja, tanto o aluno como o professor deve ser submetido a avaliações porque ensino e aprendizagem encontram-se intrinsicamente ligados exercendo uma relação de interação, de causa e consequência.
\end{abstract}

Palavras-Chave: Aprendizagem. Avaliação. Dimensões. Ensino.

\section{Assessment and its Dimensions in the Teaching-Learning Process: A Pedagogical Dynamics in the View of Hoffmann, Libâneo, Luckesi, Mello e Souza e, Sousa}

\begin{abstract}
This article analyzes about the knowledge and theories related to evaluation and its dimensions in the teaching learning process, with the objective of understanding these dimensions. Synthesizing about them in daily pedagogical praxis, the evaluation in the teaching learning process, as well as the evaluation in a mediating vision of learning based on works by Hoffmann (2017, 2019), Luckesi (1999, 2011), Libâneo (2006), Mello e Souza (2005) and Sousa (2000). Based on theoretical analysis and field research we understand that the evaluation is an inseparable and own aspect from education, through the evaluation it's possible to see if the teaching was effective to reach the students' learning, it must also to be considered as something that contributes to the moral, social and intelectual development of students. We realize that currently the evaluation is still practiced with the purpose of passing ou failing, as a classificatory end, but happily it has been getting a new aspect, being understood in a more broadly way, since it's one of the most significant components of the teaching-learning process. So, even knowing that the evaluate process is complex, the teacher must be reflective, versatile in his/her acting, he/she must continually evaluate himself/herself, because as mediator of the teaching learning process it's necessary that there's a training and action focused on the well-being and development of student, both the student and the teacher must be submitted to evaluations because teaching and learning are connected exercising a relation of interaction, of cause and consequence.
\end{abstract}

Keywords: Learning. Evaluation. Dimensions. Teaching.

\footnotetext{
${ }^{1}$ Faculdade de Ciências Humanas do Sertão Central (FACHUSC). flaviamaria.upe@ hotmail.com;

${ }^{2}$ Universidade de Pernambuco- UPE. cicera.nunes@fachusc.com
} 


\section{Introdução}

Este artigo é resultado da produção do Trabalho de Conclusão de Curso (TCC) da Faculdade de Ciências Humanas do Sertão Central (FACHUSC) em Salgueiro-PE. A curiosidade por esta pesquisa intitulada "Avaliação e suas dimensões no processo de ensino aprendizagem: uma dinâmica pedagógica na visão de Hoffmann, Libâneo, Luckesi, Mello e Souza e Sousa" surgiu no segundo semestre do ano de 2019 através da disciplina Fundamentos e Metodologia do Ensino das Ciências Naturais do curso de Pedagogia da já citada faculdade onde ao final da aula a professora que lecionava essa disciplina pedia para que os alunos avaliassem a aula. A partir disso instigou a buscar por entender a importância da avaliação no processo de ensino aprendizagem e a compreendê-la como uma ação necessária neste processo, pois a avaliação que para muitas pessoas é vista como algo negativo para a professora dessa disciplina era tratada de maneira dinâmica e natural. Então, diante do exposto este trabalho tem como problema de pesquisa: quais as dimensões da avaliação no processo de ensino aprendizagem?

À vista disso, o presente artigo teve por objetivo geral compreender as dimensões da avaliação no processo de ensino aprendizagem, sendo delineados como objetivos específicos: descrever a importância da avaliação no processo de ensino aprendizagem; analisar o conceito de avaliação em diferentes olhares e compreender a avaliação numa visão mediadora da aprendizagem.

Então, para a obtenção da resposta a essa indagação a metodologia utilizada foi a pesquisa bibliográfica com aporte teórico baseado em estudos de: Hoffmann (2017, 2019), Luckesi (1999, 2011), Libâneo (2006), Mello e Souza (2005) e Sousa (2000). Entretanto, a pesquisa avançou e necessitou de embasamento mais confidentes ou conclusivos, por isso se deu início a um estudo de campo exploratório através de questionário. Assim, para uma melhor compreensão a pesquisa foi desenvolvida seguindo a abordagem qualitativa, foram observadas as ideologias exteriorizadas pelos teóricos acima citados e pelos participantes da pesquisa de campo.

Logo, acreditamos que este artigo é de grande importância, pois os discentes e pedagogos precisam compreender o processo avaliativo, suas funções e dimensões para que assim possam usar na prática educativa instrumentos avaliativos de modo que contribuam para o bom desempenho dos estudantes, ocasionando a ascensão dos mesmos, deixando de lado a ideia de que a avaliação é uma vilã e passando a ser vista como uma das protagonistas do processo de ensino aprendizagem.

96 Id on Line Rev. Mult. Psic. V.14 N. 53, p. 95-107. Dezembro/2020 - ISSN 1981-1179 Edição eletrônica em http://idonline.emnuvens.com.br/id 
Então, as próximas seções deste trabalho apresentam o referencial teórico (As dimensões da avaliação, avaliação no processo de ensino aprendizagem e avaliação numa visão mediadora da aprendizagem), a metodologia, os resultados e discussão, as considerações finais e as referências que embasaram este artigo.

\section{Dimensões da avaliação}

No decorrer dos anos a avaliação passou por grandes transformações tanto no modo como ela é usada como na sua definição, sendo sem dúvida um dos assuntos mais discutidos e mais complexos da área educacional, pois é caracterizada por ter várias dimensões. Discorre Sousa (2000, p.101) que "é possível classificar as dimensões da avaliação segundo o espaço pedagógico que define sua atuação". Nesse sentido, apresenta as dimensões da avaliação e suas características da seguinte maneira:

A avaliação de sala de aula tem como foco o processo de ensino-aprendizagem e visa a subsidiar o aperfeiçoamento da prática docente; a avaliação institucional permite a análise da instituição educativa e indica a efetividade da instituição educativa no cumprimento de sua função social; a avaliação de programa e projetos educativos focaliza sua atenção nos propósitos e estratégias concebidos por determinado programa previsto para aperfeiçoar ou corrigir desvios de um sistema de ensino; a avaliação de currículo tem seu centro de atenção voltado para a análise do valor psicossocial dos objetivos e conteúdos propostos de um curso organizado para formar o aluno e para o estudo da efetividade dos processos previstos em sua implementação; a avaliação de sistema focaliza sistemas de ensino visando subsidiar políticas públicas na área educacional. (SOUSA, 2000, p. 101-102).

Assim, segundo Sousa (2000) a avaliação é classificada em cinco dimensões: avaliação de sala de aula, a avaliação institucional, avaliação de programa e projetos educativos, avaliação de currículo e a avaliação de sistema. Ou seja, a avaliação está presente não somente na sala de aula onde geralmente o aluno é submetido a vários tipos de avaliação como: formativa, cumulativa, diagnóstica, somativa e autoavaliação, a mesma faz parte de toda a esfera educacional como citado acima por Sousa (2000). Por isso, a avalição é muito mais abrangente do que costumamos pensar, pois envolve tudo que faz parte do universo educacional. Mello e Souza (2005) defende essa ideia dizendo:

\footnotetext{
Antes, as avaliações eram sempre dos estudantes, individualmente; hoje, busca-se avaliar instituições, o desempenho dos professores, os métodos de ensino, os programas governamentais de expansão e melhoria da educação e seu impacto, entender os condicionantes sociais dos bons e maus resultados e identificar procedimentos que possam melhorar os resultados. (MELLO E SOUZA, 2005, p. 21).
} 
Nesse sentido, a avaliação ganha dimensões mais abrangentes, pois deixou de ser de exclusividade dos estudantes e passou a ser também de todos que fazem parte do processo de ensino aprendizagem. Se os alunos são bem avaliados consequentemente os professores serão, dessa forma a instituição também será bem avaliada e receberá o reconhecimento da sociedade pelo seu trabalho. Os programas educacionais através da avaliação poderão analisar os resultados e identificar o que está bem e o que precisa ser melhorado. A avaliação possibilita ver e rever os conceitos dos resultados propiciando a melhoria das práticas dos profissionais em educação, procurando ter uma boa representatividade e repercussão. Desse modo, Luckesi (2011) diz que o ato de avaliar é caracterizado como um meio subsidiário do crescimento e da construção do resultado satisfatório. Ressalta que a avaliação subsidia a obtenção de resultados satisfatórios tanto em atos simples como complexo do nosso dia a dia.

Em nossa casa, avaliamos o alimento que estamos fazendo quando provamos seu sabor, sua rigidez, verificando se se encontra "no ponto" ou se necessita de mais algum ingrediente, de mais tempo de cozimento etc. Na empresa ocorre o mesmo. Nenhuma empresa sobreviverá sem avaliação com consequente tomada de decisão, tendo em vista seu melhor funcionamento e, por isso mesmo, sua melhor produtividade. A avaliação tem por função subsidiar a construção de resultados satisfatórios. (LUCKESI, 2011, p.183-184).

Então, é preciso entender que a avaliação é de suma importância, pois investiga o resultado de algum processo, buscando construir resultados positivos, sendo realizada em todos os segmentos, o que diferencia é o objeto a que a mesma se refere e na esfera educacional isso não é diferente. Dessa maneira, avaliar não é uma tarefa fácil, pronta e acabada. Vários são os processos que a envolve. De acordo com Libâneo (2006):

A avaliação é uma tarefa complexa que não se resume à realização de provas e atribuição de notas. A mensuração apenas proporciona dados que devem ser submetidos a uma apreciação qualitativa. A avaliação, assim, cumpre funções pedagógico-didáticas, de diagnóstico e de controle em relação às quais se recorre a instrumentos de verificação do rendimento escolar. (LIBÂNEO, 2006, p. 195).

É necessário então, extinguir a ideia de que a avaliação serve apenas para atribuir notas ao término de uma prova ou atividade. Contudo, a nota é uma exigência do sistema educacional, serve para que se tenha um parâmetro, porém o que deve ser levado mais em consideração é a qualificação do conhecimento dos alunos. Dessa forma a Lei de Diretrizes e Bases (LDB) no seu artigo 24 inciso V diz que um dos critérios para a verificação do rendimento escolar é a avaliação que deve ser contínua e cumulativa do desempenho do aluno, sendo que os aspectos qualitativos tem prevalência sobre os quantitativos e dos resultados apresentados no decorrer do período sobre as casuais provas finais. 
Portanto, a avaliação deve ser realizada continuamente e ocorrer em diferentes momentos da vida escolar, tendo como objetivo analisar os dados obtidos a fim de diagnosticar e corrigir possíveis lacunas que possam surgir, visto que, por meio da avaliação é possível averiguar se o aluno supriu as expectativas do professor e consequentemente, de acordo com o resultado o mesmo possa reparar falhas ou direcionar-se para a seguinte unidade didática.

\section{Avaliação no processo de ensino aprendizagem}

A avaliação é um instrumento fundamental no processo de ensino aprendizagem, pois é por meio da avaliação que o professor tem a noção de como os alunos estão com relação a aprendizagem, se o objetivo foi alcançado ou não. Também, é através do processo avaliativo que o educador pode identificar se a didática aplicada está satisfazendo as necessidades dos educandos. Porém, mesmo a avaliação sendo um processo tão importante e que deve trazer benefícios ainda é vista por muitos estudantes como um "bicho de sete cabeças".

Isso se dar porque o processo de ensino aprendizagem não é estático, ou seja, está em constante mudança e assim as mudanças deveriam ocorrer também com todos os processos que fazem parte desse processo maior, ensino aprendizagem, o que não deve ser diferente com o ato avaliativo, porém nem sempre isso acontece, visto que, até hoje há professores que avaliam ainda como o modelo tradicional, com o intuito de classificar os alunos como bons ou ruins, aprovados ou reprovados o que causa medo aos educandos. Ou seja, a prática de examinar é bem antiga e mesmo a avaliação ganhando força nos últimos anos, as escolas examinam com mais frequência do que avaliam. Assim, Luckesi (1999) enfatiza que:

\footnotetext{
Pais, sistema de ensino, profissionais da educação, professores e alunos, todos têm suas atenções centradas na promoção, ou não, do estudante de uma série de escolaridade para outra. O sistema de ensino está interessado nos percentuais de aprovação/reprovação do total dos educandos; os pais estão desejosos de que seus filhos avancem nas séries de escolaridade; os professores se utilizam permanentemente dos procedimentos de avaliação como elementos motivadores dos estudantes, por meio da ameaça; os estudantes estão sempre na expectativa de virem a ser aprovados ou reprovados e, para isso, servem-se dos mais variados expedientes. O nosso exercício pedagógico escolar é atravessado mais por uma pedagogia do exame que por uma pedagogia do ensino/aprendizagem. (LUCKESI, 1999, p. 18).
}

Dessa maneira, a avaliação está sendo descaracterizada de seu significado básico, pois não está acontecendo com o intuito de investigar e dinamizar a busca por conhecimentos, mas vem sendo realizada com enfoque classificatório, ou seja, não deve ser vista como uma avaliação, todavia, como um exame que tem sua importância num concurso ou processo 
seletivo, mas na educação básica não traz benefícios para o processo de ensino aprendizagem. Observamos então, que as expectativas dos pais e alunos estão voltadas para a aprovação e promoção onde os alunos querem a todo custo obter a aprovação mesmo que não tenham alcançado uma aprendizagem para tal ascensão, os professores empregam as provas como algo negativo, fazendo com que os alunos se dediquem aos estudos não por ser importante para a aquisição de conhecimentos, todavia porque se sentem ameaçados por uma prova, já o sistema de ensino pouco se importa se a aprendizagem aconteceu de forma efetiva, leva mais em consideração os números de aprovação e reprovação, não dando ênfase a qualidade da aprendizagem e os caminhos que foram percorridos para chegar ao resultado final.

Assim, o ato de avaliar deve obedecer a um conjunto de processos que envolve algumas etapas como o planejamento das atividades, a forma como será submetida aos educandos e a avaliação propriamente dita. Para Luckesi (1999):

\footnotetext{
Planejamento e avaliação são atos que estão a serviço da construção de resultados satisfatórios. Enquanto o planejamento traça previamente os caminhos, a avaliação subsidia os redirecionamentos que venham a se fazer necessários no percurso da ação. A avaliação é um ato de investigar a qualidade dos resultados intermediários ou finais de uma ação, subsidiando sempre sua melhora. (LUCKESI, 1999, p. 165).
}

Diante disso, é notório a relevância do planejamento para que a avaliação aconteça de maneira satisfatória. No entanto, o que vemos é que geralmente a avaliação é realizada apenas com o foco no resultado, ou seja, esta é uma visão um tanto equivocada já que a avaliação deve abranger o todo do aluno, a aprendizagem que ele adquire durante a sua vivência. Destarte, os processos que devem nortear a avaliação não podem ser tratados como menos importantes, mas como ações complementares para que a ação avaliativa realmente desencadeie na melhoria dos resultados.

\section{Avaliação numa visão mediadora da aprendizagem}

Em paralelo a visão tradicional da avaliação está a avaliação mediadora que defende a ideia de que o professor não deve examinar, mas avaliar de modo a identificar o que o aluno aprendeu e em que ele teve dificuldade para que assim o educador possa intervir, de modo a direcionar uma ação em busca de uma aprendizagem efetiva. Desse modo, deve-se procurar sempre ações que acarretem na melhoria do ensino e na aprendizagem do aluno. Diante disso Hoffmann (2017) afirma que avaliar, na visão mediadora, é estudar a essência da compreensão e da incompreensão dos estudantes, visto que na busca do conhecimento esse processo inclui 
de forma natural tanto progressos como regressos, sendo um processo vivido da mesma maneira pelo educador já que o mesmo é sujeito desse processo. Hoffmann (2017), ainda ressalta que:

\begin{abstract}
A avaliação é a reflexão transformada em ação. Ação, essa, que nos impulsiona a novas reflexões. Reflexão permanente do professor sobre sua realidade, e acompanhamento de todos os passos do educando na sua trajetória de construção do conhecimento. Um processo interativo, por meio do qual alunos e professores aprendem sobre si mesmo e sobre a realidade escolar no ato próprio da avaliação. (HOFFMANN, 2017, p. 24).
\end{abstract}

Através da avaliação é possível atender aos anseios dos alunos no que diz respeito ao conhecimento como um todo, já que ao refletir sobre a realidade em que os mesmos se encontram é possível tomar decisões com o objetivo de construir conhecimentos. Essa reflexão deve acontecer durante todo o processo avaliativo, constantemente. Sendo a interação um fator significativo, uma vez que é um processo que envolve tanto a figura do professor como a do aluno e que tem o intuito de trazer resultados satisfatórios para ambos. Hoffmann (2017) ainda ressalta que:

\begin{abstract}
Os erros ou as dúvidas dos alunos são considerados como episódios altamente significativos e impulsionadores da ação educativa. Permitem ao professor observar e investigar como o aluno se posiciona diante do mundo ao construir suas verdades. Nessa dimensão, avaliar é dinamizar oportunidades de autorreflexão pelo acompanhamento permanente do professor que incitará o aluno a novas questões a partir de respostas que este vai formulando. (HOFFMANN, 2017, p.27).
\end{abstract}

Assim, os erros podem ser norteadores dos acertos, não querendo dizer que para se chegar ao conhecimento seja preciso errar, porém caso aconteça episódios de dúvidas e erros é importante que o professor os observe e os investigue em prol da construção das verdades do aluno. O professor deve acompanhar o aluno de modo a despertar no mesmo a autorreflexão e novas descobertas. Desse modo, o aluno é avaliado numa perspectiva mediadora, visto que, nas palavras de Hoffmann (2017, p. 33) “observar muito, interpretar o que observa, questionar-se e questionar muito os alunos são premissas básicas dos professores que pretendem desenvolver práticas avaliativas na perspectiva mediadora."

Porém, para que a avaliação mediadora aconteça é preciso acreditar que todos os alunos estejam num processo constante de aprendizagem, tornando a evolução mais rápida na medida que os alunos sentirem confiança e segurança para exteriorizar suas ideologias e quando contarem com o suporte pedagógico para construir novos conhecimentos. Então, para Hoffmann (2019) a finalidade da avaliação mediadora é:

Sobretudo, a de desafiar o aluno a refletir sobre as noções estudadas e situações vividas, a formular e reformular seus próprios conceitos. A ação mediadora acontece, de fato, entre uma tarefa e outra do estudante à medida que o professor oportuniza 
novas vivências, novas leituras, discussões, outros procedimentos que o desafiam a pensar nas respostas formuladas até então. (HOFFMAN, 2019, p. 101-102).

Um dos focos da avaliação mediadora é explorar o conhecimento prévio do aluno, aproveitando todas as suas experiências vivenciadas e, juntamente com o conhecimento adquirido nas aulas possibilitar novos conhecimentos. Todo esse conhecimento deve ser aproveitado e o professor deve instigá-lo a desenvolver linhas de raciocínio para um crescimento efetivo das suas potencialidades.

Para que essa estratégia funcione a avaliação não pode ser estática. O seu desenvolvimento tem que acontecer no decorrer do ano escolar, já que cada aprendizagem do aluno é um passo a mais para a melhoria da sua cognição. Logo, a avaliação não deve ocorrer apenas ao final de cada bimestre, pois isso dificulta a correção das possíveis falhas, levando a não superação das dificuldades. Nesse sentido, tudo o que o aluno adquire no decorrer do ano deve ser aproveitado e isso se adquire de forma contínua. Compartilhando dessa mesma ideia Libâneo (2006) reforça da seguinte maneira:

\begin{abstract}
A avaliação escolar é um processo contínuo que deve ocorrer nos mais diferentes momentos do trabalho. A verificação e a qualificação dos resultados da aprendizagem no início, durante e no final das unidades didáticas, visam sempre diagnosticar e superar dificuldades, corrigir falhas e estimular os alunos a que continuem dedicandose aos estudos. (LIBÂNEO, 2006, p. 203).
\end{abstract}

Portanto, é importante que o professor mantenha uma coerência na preparação e execução da avaliação, pois a própria deverá buscar atingir os seus objetivos desde o princípio. Nesse sentido, as dificuldades enfrentadas pelos alunos devem ser diminuídas a cada avaliação a que ele é submetido para que haja um diagnóstico correto e que esses resultados possam ajudar na formação do aluno.

\title{
Metodologia
}

Para alcançar o objetivo proposto, o procedimento foi desenvolvido de acordo com o modelo de pesquisa bibliográfica de caráter qualitativo com aporte teórico baseado em estudos de: Hoffmann (2017, 2019), Luckesi (1999, 2011), Libâneo (2006), Mello e Souza (2005) e Sousa (2000). No entanto, a pesquisa avançou e necessitou de embasamento mais confidentes ou conclusivos, por isso se deu início a um estudo de campo exploratório através de questionário. 
A pesquisa de campo aconteceu entre os dias 24 e 28 de outubro de 2020, sendo utilizado como instrumento de coleta de dados um questionário. A amostra da pesquisa foi composta por 10 professores da segunda etapa da educação básica de escolas públicas e privadas das cidades de Parnamirim - PE, Penaforte - CE, Salgueiro - PE, e Terra Nova - PE. Os professores que participaram da pesquisa responderam as seguintes perguntas: Na sua percepção, o que é avaliação e qual a sua importância?; Quais os instrumentos de avaliação que você mais utiliza?; Em que você se fundamenta quando é necessário escolher um instrumento avaliativo?; Você avalia o desenvolvimento da aprendizagem do seu aluno apenas por atividades organizadas e preenchidas ou você avalia o seu aluno no dia a dia, ou seja de forma contínua? Para você esse método é correto? O que você faz quando o resultado da avaliação não foi o almejado?; Para você a atribuição de notas representa em sua totalidade a aprendizagem do aluno? Por quê? Você acredita que o processor deve fazer a autoavaliação, pois a mesma contribui para o desenvolvimento tanto do professor como do aluno ou a avalição só deve acontecer com os alunos? Por quê?

Apresentamos a seguir os resultados e discussão obtidos nessa investigação.

\section{Resultados e Discussão}

O tema avaliação é bastante amplo e por isso há uma gama de conceito a seu respeito. Com relação a primeira pergunta observamos que as ideias centrais dos respondentes se baseavam na percepção de que a avaliação é necessária no processo de ensino aprendizagem, sendo usada de diversas formas com o objetivo de avaliar a evolução dos alunos, medir o nível de aprendizagem dos mesmos e, ao mesmo tempo, o trabalho do professor. A avaliação é de suma importância, pois possibilita o direcionamento para as ações pedagógicas. Como diz Mello e Souza (2005, p. 31) “As avaliações de nova geração que sugiram em todo o mundo nas últimas décadas são tentativas mais ou menos bem-sucedidas de responder a problemas reais, e deverão continuar a existir, apesar de seus eventuais problemas e dificuldades." No tocante a isso queremos dizer que apesar de não saber precisamente qual é o tipo de avaliação mais eficaz, já que há controvérsias entre os professores, o que podemos afirmar é que a avaliação de modo geral é a maneira que temos de saber as dificuldades e progressos da aprendizagem do aluno.

$\mathrm{Na}$ segunda questão, os professores foram unanimes ao responder que utiliza como instrumentos de avaliação atividades escritas, porém citaram vários outros instrumentos como: roda de conversa, atividades individuais e em grupo, leitura, questionamentos, dinâmicas, além 
da observação durantes as atividades diárias. Uma das respondentes relatou que a princípio utiliza uma avaliação diagnóstica, onde pode avaliar o nível de aprendizagem do educando, costuma avaliar também o comportamento, a relação em sala de aula como um todo e no final aplica uma avaliação escrita para saber se os alunos absorveram bem o assunto estudado.

$\mathrm{Na}$ terceira questão, ao indagar sobre em que os professores se fundamentam quando precisam escolher um instrumento avaliativo os respondedores falaram que se baseiam na particularidade de cada aluno e na sua dificuldade, no nível da turma, no conteúdo que foi estudado, ou seja, é feita uma observação de como está o desenvolvimento individual dos alunos para que assim possa aplicar uma avaliação formativa.

No que diz respeito a como é avaliado o desenvolvimento da aprendizagem dos alunos todos os participantes da pesquisa disseram que a forma mais correta de avaliar é de maneira contínua, visto que a aprendizagem também é contínua, sendo assim, o desenvolvimento do aluno é observado no dia a dia e que apesar da nota da avaliação ser uma regra a ser seguida o mais importante é a aprendizagem no decorrer das aulas.

No entanto, nem sempre o resultado da avaliação é satisfatório, a partir daí o professor tem que investigar o porquê de não ter alcançado o seu objetivo. Então, nessa questão os professores indagaram que quando o resultado não é o almejado procuram usar outro método, reforçar mais os conteúdos que não foram aprendidos, replanejam as atividades, pois é preciso replanejar sempre quando o resultado não for satisfatório, afinal se algo deu errado é um sinal de que precisam melhorar, tanto na abordagem do professor como no comportamento e na aprendizagem da turma, também, é necessário que aconteça a autoavaliação seguida da retomada de conteúdo, para que possa gerar uma nova metodologia.

Ao questionar se a atribuição de notas representa em sua totalidade a aprendizagem do aluno os interrogados de modo geral responderam que não, já que o aluno pode não ter dificuldade em uma habilidade e ter em outras, assim se é aplicada uma atividade com várias habilidades se o mesmo for bem numa e for mal em outra, então a nota não pode ser geral. Um outro exemplo citado por um dos respondentes foi que muitas vezes o aluno tem o conhecimento, mas devido a um problema em casa, o nervosismo, timidez ou qualquer outro problema acaba interferindo no resultado da nota, pois se o aluno não está bem emocionalmente dificilmente tirará uma boa nota. Outro diz que dependendo da forma da avaliação um aluno considerado "bom" pode tirar uma nota ruim. Desse modo, as notas são apenas números e que não definem a aprendizagem dos alunos. 
No último quesito os professores defenderam que a autoavaliação deve acontecer constantemente, pois esse processo torna o seu trabalho mais objetivo e crítico e ainda torna o ensino mais direcionado para as reais necessidades dos alunos. Os professores precisam fazer a autoavaliação diariamente sobre a atuação e postura em sala de aula, afinal são os responsáveis pelo desenvolvimento da aprendizagem dos alunos e isso exige um trabalho qualificado e dinâmico. Precisamos também ser mais humildes, dedicados, comprometidos, amorosos, respeitados e valorizados pela sociedade e pelos governantes. O professor deve se autoavaliar só assim saberá se está agindo de forma correta, se o método utilizado está sendo eficaz e se é preciso mudar sua didática. Quando o professor se autoavalia saberá avaliar também os seus alunos, pois tudo está em constante mudança e assim os professores devem sempre procurar a melhor forma de ensinar, deve inovar-se continuamente.

Então, entendemos que a avaliação é fundamental à educação, assim acrescenta Hoffmann (2017, p. 22) que “a avaliação é essencial à educação. Inerente e indissociável enquanto concebida como problematização, questionamento, reflexão sobre a ação". Ou seja, a avaliação é um aspecto próprio e inseparável da educação, através da avaliação é possível verificar se o ensino foi eficaz para que alcançasse a aprendizagem dos alunos, deve também ser considerada como algo que contribui para o desenvolvimento intelectual, social e moral dos mesmos.

\section{Considerações Finais}

Percebemos então, que a avaliação e suas dimensões no processo de ensino aprendizagem é um assunto bastante complexo no que diz respeito a sua organização, planejamento e execução. A sua função também é bastante discutida, já que antigamente a avaliação era focada somente na questão da aprovação e reprovação e hoje deve ter um caráter mais formador, buscando a formação do cidadão, inclusive a sua formação moral e intelectual.

Existem controvérsias em relação a definição de avaliação como também a maneira mais correta de avaliar, há quem diga que a avaliação é um fenômeno indefinido. Porém o que sabemos é que a mesma faz parte do nosso dia a dia, sendo um processo mais abrangente na esfera educacional, já que os alunos, professores, escolas, sistemas de educação estão sendo submetidos constantemente aos mais variados tipos de avaliação, porém com mais frequência na figura do aluno. 
Notamos que atualmente a avaliação ainda é praticada com a finalidade de aprovar ou reprovar, como fim classificatório, porém felizmente vem ganhando uma nova roupagem, sendo entendida de uma forma mais abrangente, uma vez que é um dos componentes mais significativos do processo de ensino aprendizagem, pois através da avaliação é possível identificar erros cometidos e as dificuldades dos alunos para que a partir disso o professor possa tomar medidas a fim de mediar o aluno na construção de conhecimentos e no seu desenvolvimento preparando-o para a vida em sociedade, ambiente este que também acontece a avaliação.

Portanto, mesmo sabendo que o processo de avaliar é complexo o professor deve ser reflexivo, um polivalente na sua atuação, deve se auto avaliar continuamente, pois como mediador do processo de ensino aprendizagem é necessário que se tenha uma formação e ação voltadas para o bem estar e desenvolvimento do aluno, ou seja, ambos devem ser submetidos a avaliações porque ensino e aprendizagem estão ligados exercendo uma relação de interação, de causa e consequência.

\section{Referências}

BRASIL. Lei n. 9.394/96 - 20 de dezembro de 1996. Lei de Diretrizes e Bases da Educação.

DUARTE, Carlos Eduardo. Avaliação da aprendizagem escolar: Como os professores estão praticando a avaliação na escola. Disponível em: <http://www2.ifrn.edu.br/ojs/index.php/HOLOS/article/view/1660> Acesso em: 20 de outubro de 2020.

HOFFMANN, Jussara. Avaliação: Mito e Desafio: uma perspectiva construtivista. 45. ed. Porto Alegre: Mediação, 2017.

Avaliação Mediadora: uma prática em construção da pré-escola à universidade.

35. Ed. Porto Alegre: Mediação, 2019.

LIBÂNEO, José Carlos. Didática. São Paulo: Cortez, 2006.

LUCKESI, Cipriano Carlos. Avaliação da aprendizagem escolar: estudos e proposições. 9. ed. São Paulo: Cortez, 1999.

Cortez, 2011.

. Avaliação da aprendizagem escolar: estudos e proposições. 22. Ed. São Paulo:

MELLO E SOUZA, A. (Org.). Dimensões da avaliação educacional. Petrópolis: Vozes, 2005. 
NASCIMENTO, Mari Clair Moro; SALOMAO, Thais. A avaliação da aprendizagem na perspectiva formativa e na classificatória. Disponível em: 〈https://cutt.ly/8gYLZGP〉

Acesso em: 30 de outubro de 2020.

SOUSA, Clarilza Prado de. Dimensões Da Avaliação Educacional. Estudos em Avaliação Educacional, n. 22, 101-118, 2000.

\section{Como citar este artigo (Formato ABNT):}

SILVA, Flávia Maria da; NUNES, Cícera Alves. Avaliação e suas Dimensões no Processo de Ensino Aprendizagem: Uma Dinâmica Pedagógica na Visão de Hoffmann, Libâneo, Luckesi, Mello e Souza e, Sousa. Id on Line Rev.Mult. Psic., Dezembro/2020, vol.14, n.53, p. 95-107. ISSN: 1981-1179.

Recebido: 03/11/2020;

Aceito: 08/11/2020. 